\title{
Atomic Rare Gas Metastable Monitoring through Nitrogen Emission in Atmospheric Pressure Plasma Jets
}

\author{
Jean-Michel Pouvesle, ${ }^{\mathrm{a}, *}$ Thibault Darny, ${ }^{\mathrm{a}}$ Thomas Maho, ${ }^{\mathrm{a}}$ Vincent Puech, ${ }^{\mathrm{b}}$ \\ Claire Douat, ${ }^{a}$ Sébastien Dozias, ${ }^{a} \&$ Eric Robert ${ }^{a}$ \\ aGREMI UMR 7344 CNRS/Université d'Orléans, Orléans, France; 'LPGP UMR 8578 CNRS/ \\ Université Paris Sud, Orsay, France \\ *Address all correspondence to: Jean-Michel Pouvesle, GREMI, Université d'Orléans, 14 rue d'Issoudun, BP6744, \\ 45067 Orléans, Cedex 2, France; Tel.: +33 238417 124; Fax: +33 238417 154, E-mail: jean-michel.pouvesle@univ- \\ orleans.fr
}

\begin{abstract}
He}\left(2^{3} \mathrm{~S}\right)$ helium metastable is a key state in the energetic transfers occurring in atmospheric pressure plasma jets that are widely used for applications related to biology or material processing. Its measurement mainly relies on laser absorption, and this is not always easy to perform. In this work, we show a simple way to follow the time evolution of this state that relies on late time evolution of the transitions emitted from the $\mathrm{N}_{2}^{+}(\mathrm{B})$ state, which is mainly populated by Penning ionization from $\mathrm{He}\left(2^{3} \mathrm{~S}\right)$. Indeed, we show that the late time decay of $\mathrm{N}_{2}^{+}(\mathrm{B})$ is found to be the same as that of $\mathrm{He}\left(2^{3} \mathrm{~S}\right)$ concentration. Using previous work cited in the literature, we conclude that this type of monitoring can be used for argon metastable, with $\mathrm{N}_{2}(\mathrm{C})$ being the tracer in that case.
\end{abstract}

KEY WORDS: $\operatorname{He}\left(2^{3} \mathrm{~S}\right)$ helium metastable, argon metastable, Penning ionization, charge transfer, atmospheric pressure plasma jet

\section{INTRODUCTION}

Currently, nonthermal atmospheric pressure plasma jets are widely used for a large variety of applications in biology, medicine, agriculture, cosmetics, and material processing. This type of jet expands into the atmosphere, and important reactive oxygen and nitrogen species are created mainly after transferring energetic species of the carrier rare gas, which, in many cases, is helium. In this context, ${ }^{1}$ it is important to follow the evolution of the species concentration responsible for these transfers, particularly, the atomic metastables of helium $\left(\mathrm{He}\left[2^{3} \mathrm{~S}\right]\right)$. The usual method used is laser absorption (LA), but LA requires a setup that is rather difficult to achieve if it one desires good spatial and temporal resolution (in the case of plasma jets, this is measured in units smaller than millimeters and on nanosecond time scales). It would therefore be useful to have another simple means for measuring the population variations of this species without implementing a complex system, as is also shown in Lu et al. ${ }^{2}$ Studies carried out in the 1970s and 1980s on gas lasers, in particular, excimer lasers and charge transfer lasers, ${ }^{3}$ led to the study of reaction kinetics in atmospheric pressure media that were based on experiments involving fast direct discharges between parallel metallic electrodes over wide ranges of partial pressures of minority components in carrier gases. In experiments 
using helium/nitrogen mixtures, the emission that radiated in the transitions of nitrogen molecular ions between the $\mathrm{B}$ and $X$ states allowed investigators to follow the temporal evolution of its main population terms. ${ }^{4}$ Indeed, in helium/nitrogen plasmas, in which nitrogen is found in small amounts, the temporal evolution of the $\mathrm{N}_{2}^{+}(\mathrm{B}-X)$ transition is a result of both charge transfers from helium molecular ions that dominate in the first phase of the discharge and Penning ionization from atomic helium metastables. In the second phase of the discharge, the highly reactive molecular ions almost totally disappear, but the temporal evolution of the $\mathrm{N}_{2}^{+}$(B) state is virtually dominated by the state of production through the Penning ionization reaction. Because the radiative lifetime of the $\mathrm{N}_{2}{ }^{+}(\mathrm{B})$ state is very short $\left(67 \mathrm{~ns}^{5}\right)$ compared to the lifetime of the metastables, the temporal evolution of the $\mathrm{N}_{2}^{+}(\mathrm{B})$ that is revealed by light emission (band heads) at 391.4, 427.8 , and $470.9 \mathrm{~nm}$ follows variations of the metastable concentration.

It is therefore interesting to study whether this method, which allows us to follow the evolution of $\mathrm{He}\left(2^{3} \mathrm{~S}\right)$ in direct discharges, is also valid for plasma jet experiments. Because of the peculiar plasma shape, this measurement in such experiments is procured mainly through LA, and it is usually not easy to perform. In this work, we present a combined analysis of the metastable density measurement using spatially and temporally resolved LA for the measurement of $\mathrm{He}\left(2^{3} \mathrm{~S}\right)$, and we monitor time evolution of the $\mathrm{N}_{2}^{+}$(B) state using emission spectroscopy. Our results are clearly positive and suggest a simple way to monitor the temporal evolution of metastables. We first describe the experimental setup and then present the measurement results of the atomic metastable of helium concentration as well as the temporal evolution of the $\mathrm{N}_{2}{ }^{+}(\mathrm{B})$ state. Finally, we present an analysis of these findings together with the literature results on atomic argon metastables.

\section{EXPERIMENTAL SETUP}

The jet used in this work is from a plasma gun (PG) device. ${ }^{6}$ Figure 1 shows a schematic view of the PG. Briefly, the PG is a coaxial dielectric barrier discharge (DBD) reactor with a quartz capillary. In our work, we flushed the capillary with helium, and

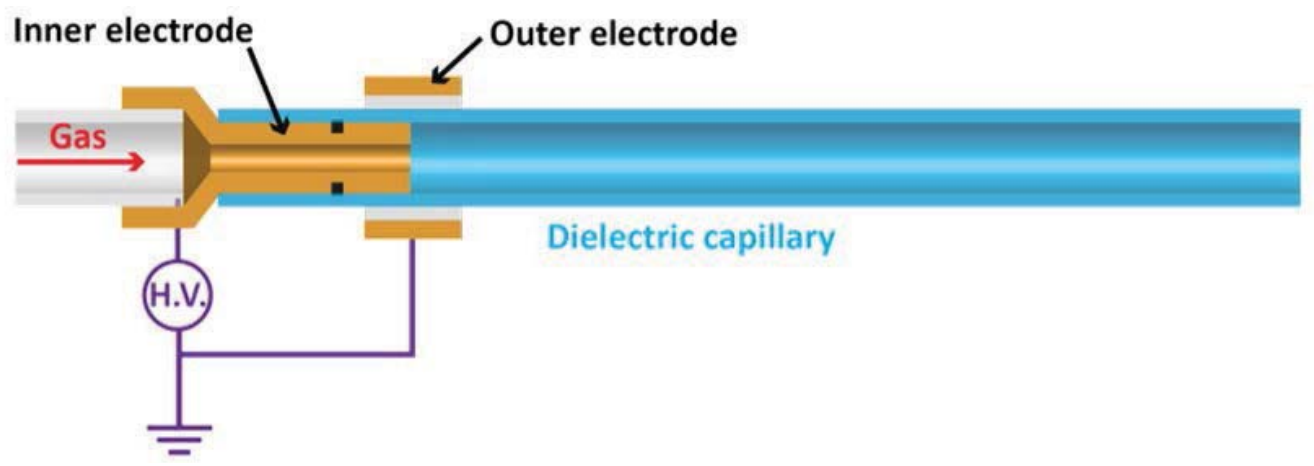

FIG. 1: PG schematic. HV, High voltage. 
it is powered by microsecond-duration voltage pulses (up to an $18-\mathrm{kV}$ peak amplitude, with either positive or negative polarity) repeated at $1 \mathrm{kHz}$, shown in Fig. 2. We used a 10.5-cm-long dielectric quartz capillary with a 4-mm inner diameter and a 6-mm outer diameter. A 2-cm-long electrode was set inside the capillary. Helium buffer (1 $\mathrm{Lmin}^{-1}$ ) or mixtures of helium $\left(1 \mathrm{Lmin}^{-1}\right)$ and nitrogen (up to $0.5 \%$ of helium flow) were injected through this inner hollowed electrode $(0.8-\mathrm{mm}$ inner diameter). A 5-mm wide grounded ring electrode was set on the outer surface of the quartz capillary overlapping downstream from the tip of the inner electrode by a few millimeters. The absolute concentration of the $\mathrm{He}\left(2^{3} \mathrm{~S}\right)$ atoms in the plasma jet was measured using LA. The setup and procedure were similar to those used by Douat et al. ${ }^{7}$ and Darny et al. ${ }^{8}$

The light source was a tunable diode laser (DL100 from TOPTICA Photonics AG, Munich, Germany) that delivered a laser beam at $1083 \mathrm{~nm}$. This wavelength was tuned to a $\mathrm{He}\left(2^{3} \mathrm{P} \leftarrow 2^{3} \mathrm{~S}\right)$ triplet transition. We measured the average $\mathrm{He}\left(2^{3} \mathrm{~S}\right)$ concentration along a line of sight (the radial axis of the jet). The laser beam diameter (i.e., the spatial resolution) was $48 \mu \mathrm{m}$, as defined by the width for which $80 \%$ power was transmitted. A step-by-step motor allowed micrometric translation of the PG; the whole capillary and plasma plume were probed vertically on the jet symmetry axis. We averaged the $\mathrm{He}\left(2^{3} \mathrm{~S}\right)$ concentration measurement using 400 pulses and assumed absorption length to be $4 \mathrm{~mm}$ (capillary inner diameter); however, in positive polarity, because of the discharge filamentary structure, absorption length was overestimated and led to an underestimated absolute concentration value for this polarity. $\mathrm{N}_{2}{ }^{+}(\mathrm{B}-X)$ emission was recorded at $391.4 \mathrm{~nm}$ (an average of 512 pulses) using an Acton VM series Vacuum Monochromator (VM-504) from Princeton Instruments (Roper Scientific, Every, France) with an R955 Hamamatsu (Hamamatsu Photonics, Massy, France) photomultiplier tube through an optic mounting. This allowed us to gather the light emitted over $5 \mathrm{~mm}$ along the capillary, and this induced a time blurring of

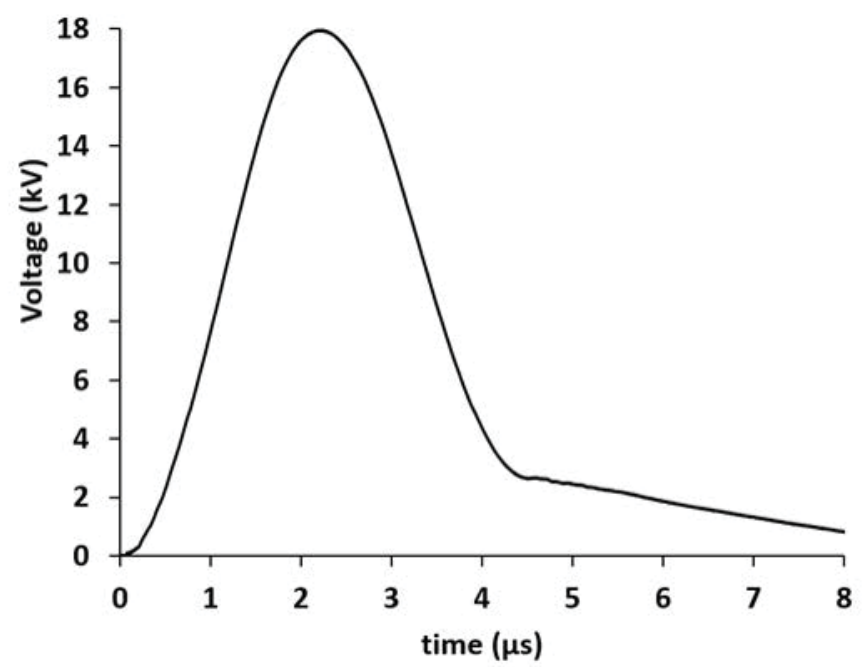

FIG. 2: High voltage pulse temporal evolution 
$\sim 50 \mathrm{~ns}$ taking into account the velocity at which the plasma is propagating in the capillary. Four different sets of experiments were analyzed. The first used a high-purity system (device 1) for the $\mathrm{He}\left(2^{3} \mathrm{~S}\right) \mathrm{LA}$ measurements. The second used a more conventional system (device 2) for biological experiments for $\mathrm{N}_{2}^{+}(\mathrm{B}-X)$ spectroscopy, that had a much higher level of impurity due to the use of plastic tubing. The third was used only in helium with device 2, for which most of the plastic tubing was replaced by stainless steel (ss) tubing. The last system had an even higher level of impurities (device 3).

\section{RESULTS AND DISC USSON}

Figures 3 and 4 show typical data obtained, respectively, for the $\mathrm{He}\left(2^{3} \mathrm{~S}\right)$ and $\mathrm{N}_{2}{ }^{+}(\mathrm{B})$ states time evolutions (semilog plot) in the capillary at the same distance from the DBD reactor $(5.5 \mathrm{~cm}$ downstream from the grounded ring electrode) in the case of a $0.1 \%$ admixture of $\mathrm{N}_{2}$ in He. It can be seen in Fig. 3 that the decay of He metastable is almost mono-exponential, whereas, as expected, the time evolution of the $\mathrm{N}_{2}^{+}(\mathrm{B})$ state (Fig. 4) after its maximum intensity presents two different phases. A rapid first phase corresponds to the period during which charge transfer from $\mathrm{He}_{2}{ }^{+}$ions is dominant, following the reactions in Eqs. (1) and (2), and a second charge transfer is much slower and corresponds to the period during which the $\mathrm{N}_{2}^{+}(\mathrm{B})$ state is mainly populated through Penning ionization following the reactions in Eqs. (3) and (4). The second slope corresponds to the decay of the metastables shown in Fig. 3. Finally, analysis of the late time slope of $\mathrm{N}_{2}^{+}(\mathrm{B})$ can infer the time evolution of $\mathrm{He}\left(2^{3} \mathrm{~S}\right)$.

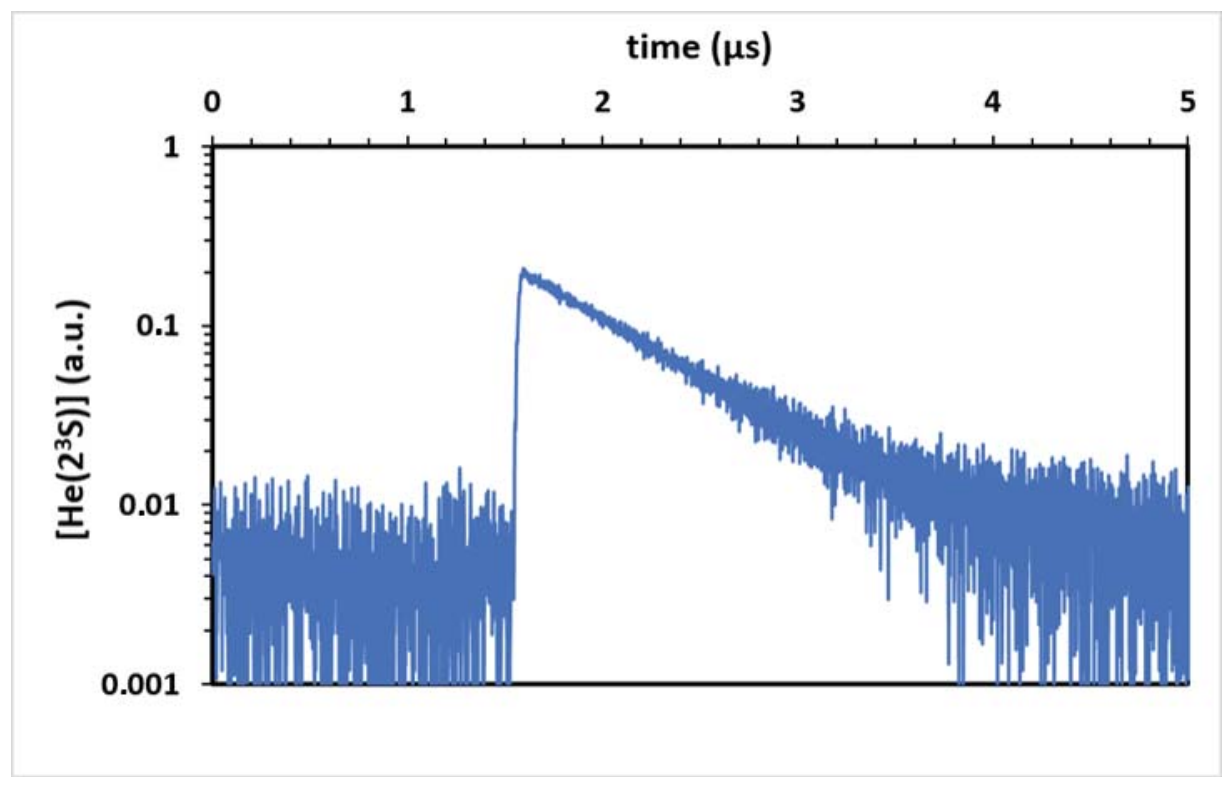

FIG. 3: $\mathrm{He}\left(2^{3} \mathrm{~S}\right)$ time evolution measured by LA for $0.1 \%$ admixture of $\mathrm{N}_{2}$ in helium: $18 \mathrm{kV}$, positive polarity, device 1 


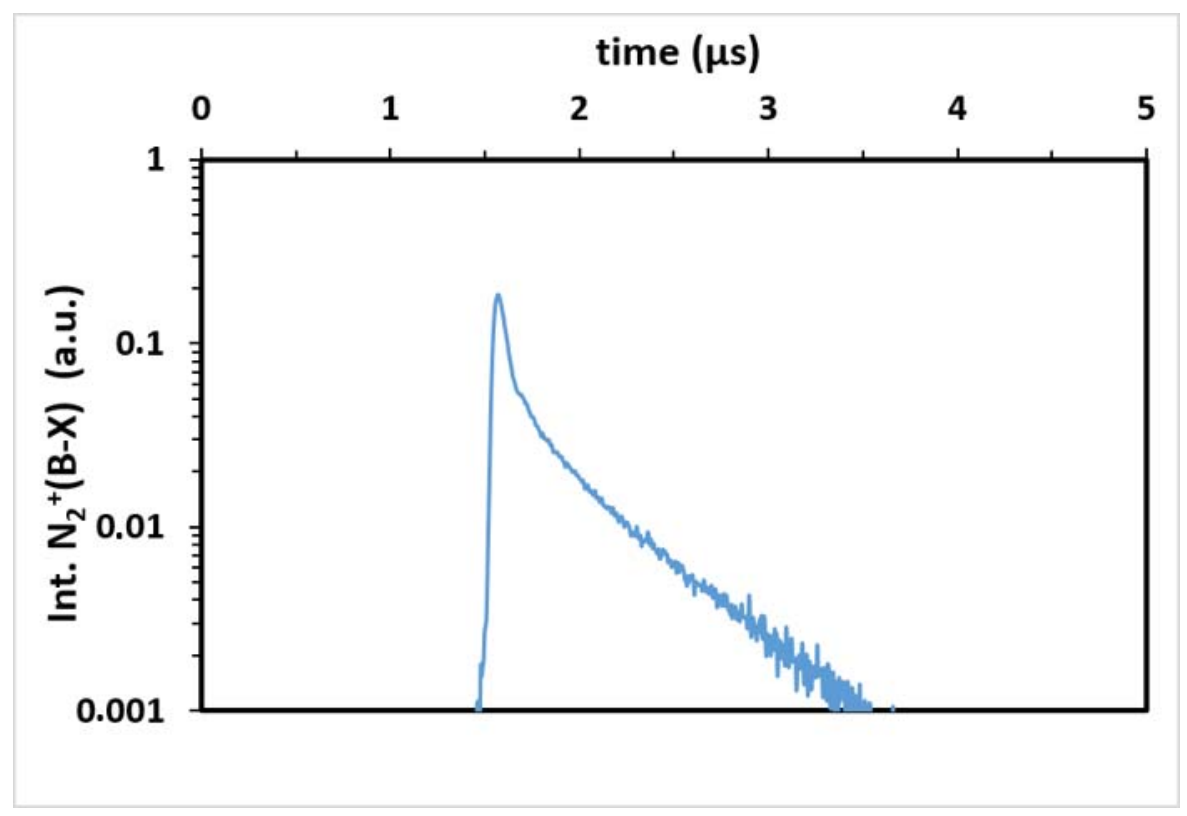

FIG. 4: $\mathrm{N}_{2}{ }^{+}(\mathrm{B}-X)$ transition $(391.4 \mathrm{~nm})$ time evolution for $0.1 \%$ admixture of $\mathrm{N}_{2}$ in helium: 16 $\mathrm{kV}$, positive polarity, device 2

$$
\begin{gathered}
\mathrm{He}_{2}^{+}+\mathrm{N}_{2} \rightarrow \mathrm{N}_{2}^{+}(\mathrm{B})+2 \mathrm{He}, \\
\mathrm{He}_{2}^{+}+\mathrm{N}_{2}+\mathrm{He} \rightarrow \mathrm{N}_{2}^{+}(\mathrm{B})+3 \mathrm{He}, \\
\mathrm{He}^{3}\left(2^{3} \mathrm{~S}\right)+\mathrm{N}_{2} \rightarrow \mathrm{N}_{2}^{+}(\mathrm{B})+\mathrm{He}+e, \\
\mathrm{He}\left(2^{3} \mathrm{~S}\right)+\mathrm{N}_{2}+\mathrm{He} \rightarrow \mathrm{N}_{2}^{+}(\mathrm{B})+2 \mathrm{He}+e .
\end{gathered}
$$

When $\mathrm{N}_{2}$ concentration increases, He molecular ions are destroyed very efficiently, and their contribution to $\mathrm{N}_{2}^{+}(\mathrm{B})$ is slightly reduced, leading to a time evolution of that state that is very close ( $100 \mathrm{~ns}$ after the peak intensity) to the measured decay of the He metastables. This is shown in Fig. 5 for the case of the $0.5 \% \mathrm{~N}_{2}$ admixture in $\mathrm{He}$.

If Eqs. (3) and (4) are the main reactions leading to the destruction of $\mathrm{He}\left(2^{3} \mathrm{~S}\right)$, the destruction frequency of the atomic metastable can be derived as follows:

$$
v_{m}=v_{0}+k_{m}\left[\mathrm{~N}_{2}\right]
$$

where $v_{0}$ represents the intrinsic losses in so-called pure helium (that results from the real, pure helium reaction kinetics and takes into account quenching by all impurities including traces of nitrogen). $k_{m}=k_{3+} k_{4}(\mathrm{He})$ is the global rate coefficient for the reactions of $\mathrm{N}_{2}$, with the atomic helium metastables $k_{3}$ and $k_{4}$ the rate coefficients of Eqs. (3) and (4). It must be noted that the rate coefficient $k_{m}$ that can be deducted from $\mathrm{He}\left(2^{3} \mathrm{~S}\right)$ destruction frequencies versus nitrogen concentrations may be slightly influenced by the 


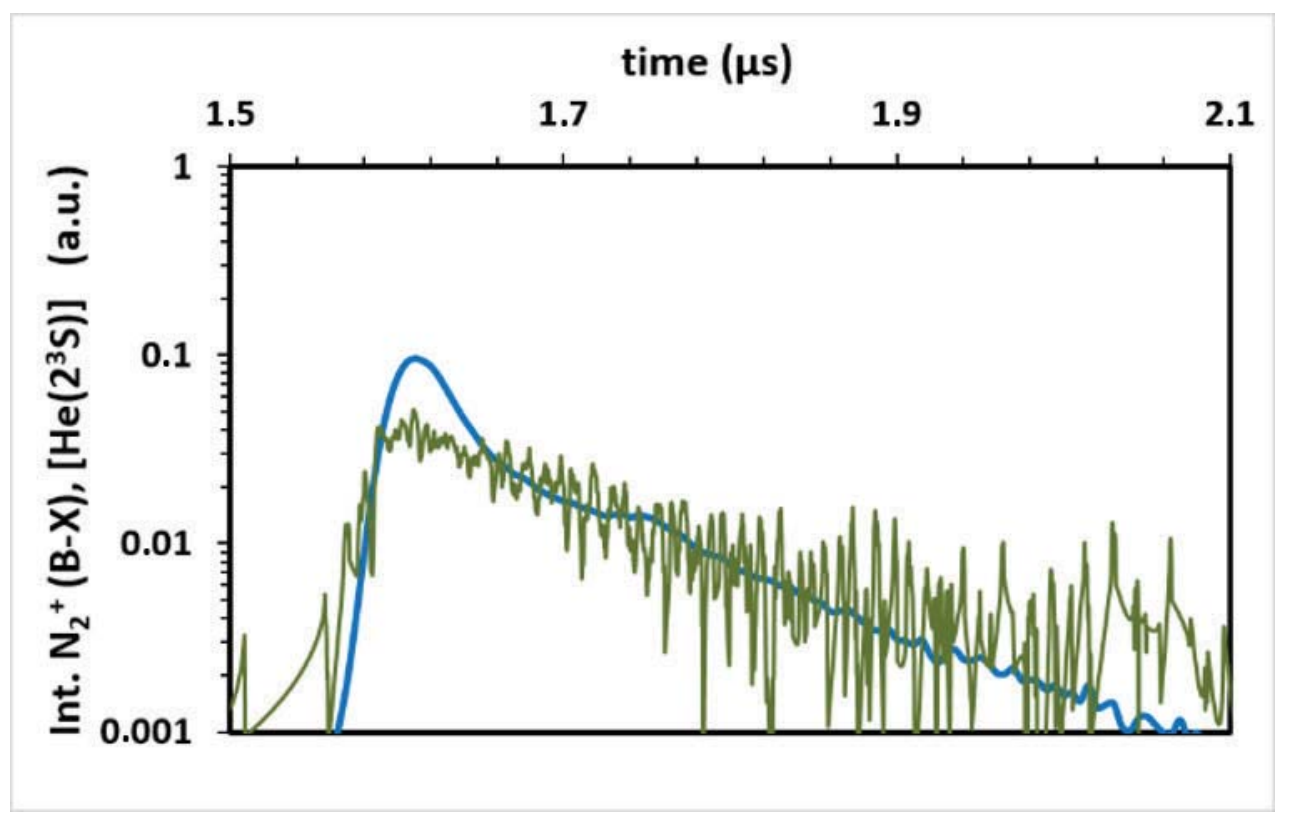

FIG. 5: (Green straight curve) Time evolution comparison of $\mathrm{He}\left(2^{3} \mathrm{~S}\right)$ using device 1; (blue smooth curve) $\mathrm{N}_{2}^{+}($B) states using device 2 . Both are for a $0.5 \%$ nitrogen admixture to helium.

effect of nitrogen reactions with other atomic and molecular states, including Rydberg molecules that may stay highly populated during a long portion of the plasma evolution. ${ }^{9}$ This can interfere with global equilibrium among all of the $\mathrm{He}$ and $\mathrm{He}_{2}$ excited states that are also populated through $\mathrm{He}_{2}{ }^{+}$recombination. The evolution of $\mathrm{He}\left(2^{3} \mathrm{~S}\right)$ destruction frequency versus nitrogen percentage deduced from LA measurements (using device 1) is shown in Fig. 6, together with the late time destruction frequency of $\mathrm{N}_{2}^{+}(\mathrm{B})$ deduced from the emission at $391.4 \mathrm{~nm}$ (using device 2). From this graph, two main conclusions may be drawn. First, the extracted value of $k_{m}$ from direct measurements of the atomic metastable concentration $6.5 \pm 0.7 \times 10^{-11} \mathrm{~cm}^{3} \mathrm{~s}^{-1}$ is in quite good agreement with previously reported values at atmospheric pressure. ${ }^{4}$ Second, the deduced value of $k_{m}$ through the proposed analysis of the late slope of $\mathrm{N}_{2}^{+}(\mathrm{B})$ emission is very close to the preceding value of $6.1 \pm 0.5 \times 10^{-11} \mathrm{~cm}^{3} \mathrm{~s}^{-1}$. This indicates that $\mathrm{N}_{2}^{+}(\mathrm{B})$ production is mainly dominated by the reactions depicted in Eqs. (3) and (4). Such a result implies that late time evolution of the $\mathrm{N}_{2}{ }^{+}(\mathrm{B}-X)$ transition can clearly be used to follow the atomic helium metastable evolution in plasmas obtained during plasma jet experiments anywhere in the course of the plasma stream (in this case, $5.5 \mathrm{~cm}$ in the capillary). The difference in $v_{0}$ between the two series of measurements realized using two separate devices is a function of the difference in impurity levels between the two systems used for those experiments. The lowest value of $v_{0}\left(3.5 \times 10^{5} \mathrm{~s}^{-1}\right)$ obtained in the highest purity conditions (device 1) gives a good indication of the effect of intrinsic losses due to other processes in pure helium and those induced by the very low, remaining impurities 


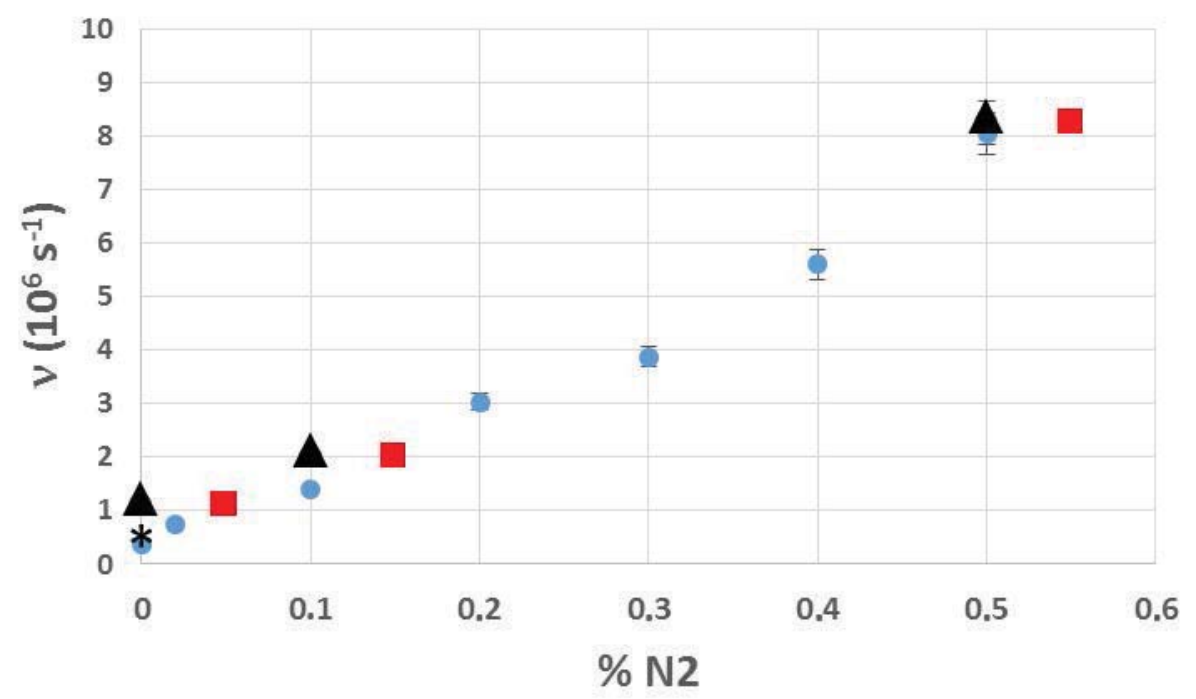

FIG. 6: $\mathrm{He}\left(2^{3} \mathrm{~S}\right)$ (device 1, blue dots) and late time $\mathrm{N}_{2}{ }^{+}(\mathrm{B})$ (device 2, black triangles) destruction frequencies versus percentage of nitrogen admixture to helium. Red squares correspond to $\mathrm{N}_{2}^{+}$(B) destruction frequencies shifted by $0.05 \%$ on the abscissa axis. The star corresponds to $\mathrm{N}_{2}^{+}$(B) destruction frequency in "pure" helium in device 2 equipped with ss tubing.

(mainly occurring inside the gas bottle). The highest value $\left(1.1 \times 10^{6} \mathrm{~s}^{-1}\right)$ obtained with device 2 (using plastic tubing) corresponds to an equivalent level of $\mathrm{N}_{2}$ impurities of $0.05 \%$, compared to the results obtained directly with LA measurements. If the results obtained with device 2 are shifted by $0.05 \%$ on the abscissa axis (Fig. 6, gray dots), it can be seen that the late time $\mathrm{N}_{2}^{+}(\mathrm{B})$ destruction frequencies agree almost perfectly with those of $\mathrm{He}\left(2^{3} \mathrm{~S}\right)$. Taking the above $v_{0}$ given value into account, the analysis of the late time slope of the $\mathrm{N}_{2}^{+}(\mathrm{B}-X)$ transition in so-called pure helium can yield a good appreciation of the purity of the helium gas used in a given reactor. Therefore, it must be stressed that changes in the flow rate or tubing materials for a given system will lead to changes in $v_{0}$ value, as has already been shown in the literature. ${ }^{7,10}$ Changing most of the tubing from PVC plastic to ss and increasing the helium flow to $2 \mathrm{~L} / \mathrm{min}$ in device 2 brought $v_{0}$ to a value of $5.4 \times 10^{5} \mathrm{~s}^{-1}$, close to that of the high purity system (device 1 ). We performed the same experiments with varied nitrogen concentrations with device 3 , the system with even higher levels of impurities, reasoning that it would lead to higher translated destruction frequency while maintaining the slope from which the rate coefficient $k_{m}$ was deduced. Those results are shown on Fig. 7. Once again, the deduced value of $k_{m}\left(6.6 \pm 0.5 \times 10^{-11} \mathrm{~cm}^{3} \mathrm{~s}^{-1}\right)$ from the linear fit of the data is in very good agreement with previous values. In this case, $v_{0}$ corresponds to an equivalent level of $0.1 \%$. This value reflects the destruction of $\mathrm{He}\left(2^{3} \mathrm{~S}\right)$ from any impurity of feeding gas, water coming from residual humidity in the tubing, and ambient air leaking backward into the capillary. Thus, the proposed method presents a simple means to follow changes in 


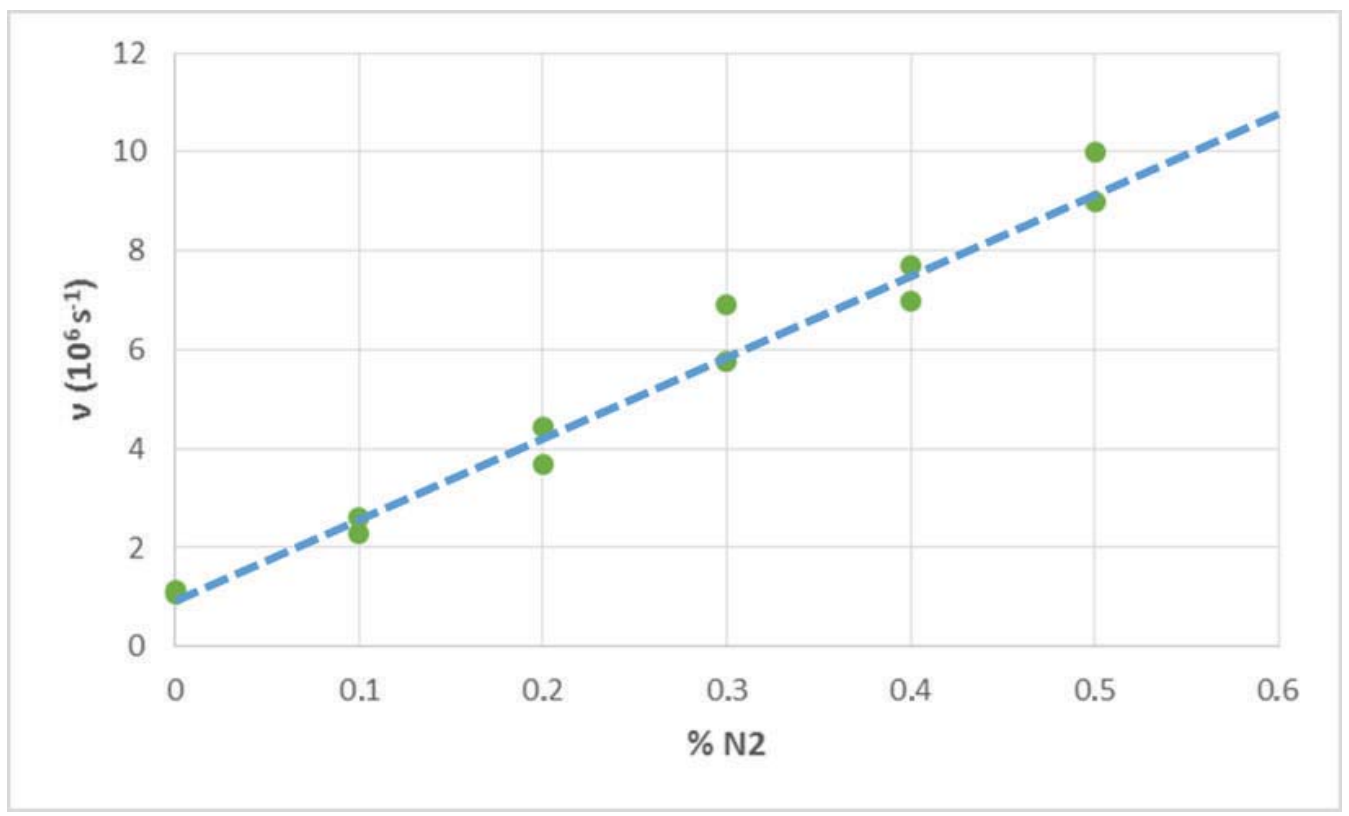

FIG. 7: Late time $\mathrm{N}_{2}^{+}($B) (device 3) destruction frequencies versus percentage of nitrogen admixture to helium. The blue dashed line corresponds to the linear fit of the data points.

helium purity along a capillary open to the air or other medium at its end. These results may be correlated with those of Sands et al. ${ }^{11}$ concerning argon metastables $\operatorname{Ar}(1 \mathrm{~s} 5)$ in a streamer-like helium-argon atmospheric pressure plasma jet. These authors measured Ar metastable concentrations using LA at $811.5 \mathrm{~nm}$ and compared their results with the decay of the transition $\mathrm{N}_{2}(\mathrm{C}-\mathrm{B})$ at $337 \mathrm{~nm}$, for which the $\mathrm{N}_{2}(\mathrm{C})$ state can be produced through the excitation transfer reaction as follows:

$$
\operatorname{Ar}(1 \mathrm{~s} 5)+\mathrm{N}_{2} \rightarrow \mathrm{N}_{2}(\mathrm{C})+\operatorname{Ar} .
$$

In a similar manner to $\mathrm{N}_{2}^{+}(\mathrm{B})$ in the case of a reaction with atomic helium metastables, $\mathrm{N}_{2}(\mathrm{C})$ has a very short radiative lifetime $\left(41 \mathrm{~ns}^{5}\right)$ compared to that of the atomic argon metastable. It it can be thus deduced that $\mathrm{N}_{2}(\mathrm{C})$ evolution will follow that of Ar metastables, assuming that the excitation transfer occurs essentially through that species. Indeed, Sands et al. ${ }^{11}$ found that decay rates of $\mathrm{N}_{2}(\mathrm{C})$ emission and $\operatorname{Ar}(1 \mathrm{~s} 5)$ agree to within $10 \%$, after passage of the ionization front. $\mathrm{N}_{2}(\mathrm{C})$ may thus be used to monitor atomic argon metastables on a long time decay. These results together with those presented in this work show that traces of nitrogen can be used in a large variety of plasma jet experiments, pure gases, and gas mixtures to monitor the time evolution of rare-gas (He and Ar) atomic metastables. These metastables play a very important part in plasma jet-induced chemistry, as long as the metastable lifetime in the discharge is much longer than the radiative lifetime of the monitoring state. 


\section{IV.CONCLUSION}

We studied the possibility of monitoring atomic helium metastables $\mathrm{He}\left(2^{3} \mathrm{~S}\right)$ in plasma jet experiments using helium/nitrogen mixtures following the late time decay of the $\mathrm{N}_{2}^{+}(\mathrm{B})$ state. We measured $\mathrm{He}\left(2^{3} \mathrm{~S}\right)$ concentrations using LA and followed $\mathrm{N}_{2}{ }^{+}(\mathrm{B})$ time evolution through $\mathrm{N}_{2}{ }^{+}(\mathrm{B}-X)$ transitions at $391.4 \mathrm{~nm}$. The measurements recorded for a wide range of $\mathrm{He} / \mathrm{N}_{2}$ mixtures revealed that both $\mathrm{He}\left(2^{3} \mathrm{~S}\right)$ and $\mathrm{N}_{2}{ }^{+}(\mathrm{B})$ states exhibit the same late time destruction frequency and lead to an estimated value $(6.4 \pm 0.7 \times$ $\left.10^{-11} \mathrm{~cm}^{3} \mathrm{~s}^{-1}\right)$ of the Penning ionization rate coefficient of $\mathrm{N}_{2}$ by $\mathrm{He}\left(2^{3} \mathrm{~S}\right)$ at atmospheric pressure. Our results are in good agreement with values reported in the literature $\left(7-8 \times 10^{-11} \mathrm{~cm}^{3} \mathrm{~s}^{-1}\right.$; see Pouvesle et al. $\left.{ }^{12}\right)$. This indicates that in the second phase of postdischarge, the $\mathrm{N}_{2}{ }^{+}(\mathrm{B})$ state is an accurate tracer of atomic helium metastable time evolution, as has already been shown in direct fast discharges dedicated to a charge transfer laser. This also reveals that measuring $\mathrm{N}_{2}{ }^{+}(\mathrm{B})$ late time postdischarge destruction frequency in so-called pure helium can give a good idea of the impurity levels by which $\mathrm{He}\left(2^{3} \mathrm{~S}\right)$ is efficiently quenched. In the same manner, it can yield a very good estimation of the variation of air/helium mixture in a plasma plume. Thus, monitoring $\mathrm{He}\left(2^{3} \mathrm{~S}\right)$ through $\mathrm{N}_{2}{ }^{+}(\mathrm{B}-X)$ transitions appears to be very convenient for the study of atmospheric pressure plasma jets and their various applications. From the work reported in Sands et al., ${ }^{11}$ we can extend this type of measurement using $\mathrm{N}_{2}{ }^{+}(\mathrm{B}-X)$ and $\mathrm{N}_{2}(\mathrm{C}-\mathrm{B})$ transitions to helium and argon or their mixtures to follow the evolution of atomic metastables that have a crucial role in any chemistry induced by atmospheric pressure plasma jet.

\section{ACKNOWEDGMENT}

This work was partly funded by the Agence Nationale de la Recherche Programme Blanc 093003 PAMPA.

\section{REFERENCES}

1. Ono R. Optical diagnostics of reactive species in atmospheric-pressure nonthermal plasma. J Phys D Appl Phys. 2016;49:83001.

2. Lu X, Naidis GV, Laroussi M, Reuter S, Graves D B, Ostrikov K. Reactive species in non-equilibrium atmospheric-pressure plasmas: Generation, transport, and biological effects. Phys Rep. 2016;630:1.

3. Collins CB, Cunningham AJ, Curry SM, Johnson BW, Stockton M. Stimulated emission from charge-transfer reactions in the afterglow of an e-beam discharge into high-pressure. Appl Phys Lett. 1974;24:477.

4. Pouvesle JM, Bouchoule A, Stevefelt J. Modeling of the charge transfer afterglow excited by intense electrical discharges in high pressure helium nitrogen mixtures. J Chem Phys. 1982;77:817.

5. Wuerker RF, Schmitz L, Fukuchi T, Straus P. Lifetime measurements of the excited states of $\mathrm{N}_{2}$ and $\mathrm{N}_{2}^{+}$ by laser-induced fluorescence. Chem Phys Lett. 1988;150:443-6.

6. Robert E, Sarron V, Riès D, Dozias S, Vandamme M, Pouvesle JM. Characterization of pulsed atmospheric-pressure plasma streams (PAPS) generated by a plasma gun. Plasma Sources Sci Technol. 2012;21:034017.

Volume 8, Issue 1, 2018 
7. Douat C, Kacem I, Sadeghi N, Bauville G, Fleury M, Puech V. Space-time resolved density of helium metastable atoms in a nanosecond pulsed plasma jet: Influence of high voltage and pulse frequency. $\mathrm{J}$ Phys D Appl Phys. 2016;49:285204.

8. Darny T, Pouvesle J, Puech V, Douat C, Dozias S, Robert E. Analysis of conductive target influence in plasma jet experiments through helium metastable and electric field measurements. Plasma Sources Sci Technol. 2017;26:45008.

9. Schregel C, Carbone EAD, Luggenhölscher D, Czarnetzki U. Ignition and afterglow dynamics of a high pressure nanosecond pulsed helium micro-discharge. I. Electron, Rydberg molecules and $\mathrm{He}\left(2^{3} \mathrm{~S}\right)$ densities. Plasma Sources Sci Technol. 2016;25:54003.

10. Niermann B, Kanitz A, Böke M, Winter J. Impurity intrusion in radio-frequency micro-plasma jets operated in ambient air. J Phys D Appl Phys. 2011;44:325201.

11. Sands BL, Leiweke RJ, Ganguly BN. Spatiotemporally resolved $\operatorname{Ar}(1 \mathrm{~s} 5)$ metastable measurements in a streamer-like He/Ar atmospheric pressure plasma jet. J Phys D Appl Phys. 2010;43:282001.

12. Pouvesle JM, Khacef A, Stevefelt J, Jahani H, Gylys VT, Collins CB. Study of two-body and threebody channels for the reaction of metastable helium atoms with selected atomic and molecular species. J Chem Phys. 1988;88:3061. 